\title{
Communication in the context of war: the need to inform and reserve requirement
}

Keywords: communication, observations, statements, reserve, requirement, opposite, ambiguity

\section{Mini review}

I would like at the start of this paper by stating some observations that will help me later to plant better the decoration of the relationship between the two antithetical forms that is the title of the topic. It is about (namely) the need to inform that sounds as a requirement for journalists, on the one hand, and the reserve requirement which is not least but opposite to the first second. These unbalanced statements or agonistic emphasize the constitutive ambiguity of communication in times of war that it is permissible here to watch the full extent. My intention is not to put on trial this reversal even this sense of collision between what for journalists may appear as a categorical imperative professional the need to inform The communicators main objective to sell the war, on the one hand. The idea that this need must be combined with the obligation to reserve, which is a general provision that can only be a chain mail to the press, on the other side. I realize that despite everything that is expected of me here is to place under the spur of a proselytizing standard journalistic patriotism that is reminiscent of economic patriotism, and who wants protector of territorial integrity and values that protect the Islamist and terrorist propaganda.

The problem is as follows: first, the war of communication is information warfare. It is often summed up in war reporting and presents itself as a work of framing and formatting to show gun violence and its real effects (allies/ enemies, winners/losers, civil/ military, wounded, and dead) from a perspective that is certainly nothing but a point of view but whose obvious aim is to provide a specific focus on the war. One could describe this practice as "embedded" embedded journalism, to indicate the direction of model pools of journalists where we need to uphold an angle (war seen from below or from above). But the war of communication aims to stage a thrilling representation of its own fights, ennoble and fetish national defense and because leaves some easy to use stereotypes to expose the enemy to the world and the history of court. Everything plays here in the power of words and images whose power has transformed the war by transferring the field of legitimation: justification, representation and the argument becomes the new challenges of communication of war and mobilizes new strategies. Two consequences will ensue, double professional and ideological. Everything plays here in the power of words and images whose power has transformed the war by transferring the field of legitimation: justification, representation and the argument becomes the new challenges of communication or war and mobilizes new strategies.

In the first case, as it is to make the "presentable" war, the use of propaganda magnified by the contribution of information and communications technology mobilizes influential agencies and load the cosmétiser because one while demonizing the enemy. For François-Bernard Huyges, ${ }^{1}$ author of a remarkable book on the communication war, "allis as if the war of communication entrusted to professionals could succeed the political and resolve the challenges
Volume 3 Issue 3 - 2019

\author{
Di Michèle Ngoyo Mekeme,' Laurent \\ Charles Boyomo Assala ${ }^{2}$ \\ 'Advanced School of Mass Communication, University of \\ Yaounde II, Cameroon \\ ${ }^{2}$ Department of Communication and Civilization, University of \\ Yaounde II, Cameroon
}

Correspondence: Di Michèle Ngoyo Mekeme, IAdvanced School of Mass Communication, University of Yaounde II, Cameroon, Email cboyomo@yahoo.fr

Received: March 21, 2019 | Published: May 27, 2019

facing a nation at war: - justify from an opinion that does not react with a patriotic reflex membership since the declaration of war mainstream of international opinion - make the conduct of the war more acceptable for a "hearing" that welcomes more systematically to see inflict maximum damage to enemies (as for centuries, it was rather pleased that his side do what Canetti calls "a big pile of dead").

Concealment of horror called complement stimulation action (demonization, even "hitlerization" the opponent as during the war "humanitarian" Kosovo) to play on the reflex of public opinion. This also suggests a simulation strategy (provide the press images of the victims good or good heroes, almost mounted scenes war to make it acceptable to viewers accustomed to fiction codes). "In the second case, although often unfortunately, the call to the media patriotism boils down to imposing a blind silence, and to impose on journalists threat exceptional provisions of the regulation. Hence the recourse to the notion of reserve requirement which the administrative denomination is called censorship, this spectrum of media work. But by focusing the debate instead of censorship in the communications war, we lose sight of the key issue is that news coverage of the war is primarily a professional performance. For the essence of journalism is polemological least in the difficulty he has to account for the war as a "total" event, seen through a hypothetical media panopticon, to assume a controlled manner the psychology of violence it carries. The mobilized media device actually involves, expertise overlooking the courage implied by the presence on the ground of hostilities to question the ethical and technical heritage of the journalist. If technically setting images, writings and sounds partly imposed by the device external constraints of the context of war, the argumentative register remains meanwhile the area of arbitrations editorial morality. Because in the circumstances, the discursive register of symbolic violence is unlimited: the dead show the image or text by using the elasticity of rhetoric, metaphor and metonymy, giving echo to armed violence, trivialize the killing under the symbolic mask lexicon. But often the fights are associated with illegal operations under the summary justice, assassinations and massacres, summary executions 
and rape. And the war situation is conducive to the prosperity of the rhetoric of war presented as a blind amok, while it is actually the result of a deliberate will to dominate the opponent firearms course, but also on the front of the ideology of images and words, in which the powerful images of flag-waving nations and triumphant compete with low images submitted and absolved armies. Summary executions and rape. And the war situation is conducive to the prosperity of the rhetoric of war presented as a blind amok, while it is actually the result of a deliberate will to dominate the opponent firearms course, but also on the front of the ideology of images and words, in which the powerful images of flag-waving nations and triumphant compete with low images submitted and absolved armies.

Military authorities rarely escape the temptation to control the information war whose risk and difficulties make their preferred communication war. There is therefore reason to fear that in the rhetoric of the reserve requirement censorship of information maquée advance. One of the ideological presuppositions of polemological communication which is a communication under control staffs - has indeed named operational communication. This means the communication on military operations and is reserved in our higher schools of the Defense Forces military teachers. It's a double-barreled strategy to minimize the risk of diarrhea / unveiling strategies armies in time of war, on the one hand; and secondly to keep the army mysterious power to persuade through communication by focusing on revenue technological. Real geostrategic tool, operational actual communication have increasingly the ultimate virtue to offer media journalism from the knowledge of their mode of operation, a large number of ready-to-disseminate that exonerate the field work product. But this mechanistic view is facing some economic difficulties especially related to media periodization devices, the widespread use of the Internet by the warring parties of all stripes, Rest invoking the obligation of discretion legally vague principle, which in classical law resulted in the requirement for an official to abstain from all about involving the institution it serves. Unless you consider that any journalist working for public media is an official and that all media covering a war assimilated or compelled to public service, the argument of this obligation is void legal sense but not stripped of professional meaning, professional reserve here taking the sense of a journalistic value guiding the field approach to avoid include yielding to the media voyeurism.

In short, the problem that is posed here is summed up in simple words: what is the information/ communication on the war? For professional and political debates often tend to hide here as elsewhere the real terms and issues in social activities. For the occasion might contain info-communicational issue in the order of public access to information, answering him with a desire and a need to know. These basic truths are rarely recalled in strategic thinking. It is clear that it serves to maximize social utility functions of various actors: armed officers, experts in strategic communication and law studies and other think tanks, journalists and media structures. It is also true that the war is also a communicative exchange market where products that a number of specialists trained to be "unique" qualities "immeasurable" by storing them "professionals" including "the intervention wants more adjusted possible to the specific problems of individuals and communities. "Karpik Lucien ${ }^{2}$ but the communicative theory has evolved and these days seem to favor the recipient's point of view to that of the sender. The war of communication from the perspective of recipient builds its utilities between curiosity and necessity. It indeed provides knowledge necessary for individual and collective life, the exercise of an activity and social life. Finally, it contributes to the satisfaction of curiosity. All this is determined by economic, social and cultural constraints, it can achieve this social utility function when it is governed by an ideal that goes beyond and overlooks the context of war itself to attain to the fullness of his petrol. Reporters to find the principles and methods of their work and whose flag the public interest. Beyond the normative and policy provisions.

It is appropriate at this stage to dwell specifically on the particular action exerted terrorism on communication. If indeed collusion between spectacularization violence and political power has been the subject of many studies, how the terrorist attacks are part of the public space is not subject to those fairly recent elaborations. It also points out the difference between the communication war actions by armies in the field and "the fight against imaginary"3 of terrorism. Here the desired psychological effects are of a different nature than the material effects of conventional warfare. The central objective in the impact that the attack will have on the public, two types of links appear to be between terrorist action and the media, the first organic underlines the inability of the latter to exonerate; the second link, functional one, sure from what Mannoni calls "the law of the spread," a multiplier, the results out of proportion to the small "firecracker" he blasted. To this is added according to author a number of functional and structural characteristics of the media: eagerness of the press to report on hot events, competition in the show which forces quick reactions, particularly violent television exerted in Bourdieu with the same complicity viewers, directed exacerbated images. The media as well end up being they manipulated (Tjade) even held hostage in circumstances that ultimately benefit the terrorists. Under the communication angle, the terrorist phenomenon is an act of "rogue" (Garcin-Marrou) forcing the media to produce a rationalized discourse on violence that exceeds the rationality itself and deeply undermines the founding principles of a democratic community. And analysis of the pivots of journalistic discourse demonstrates the paradoxes of formal words that seek to stick to the facts without emancipation comments called for by the violence. It reveals the cognitive contradictions journalists in contact with this violence itself as blind to better hide the philosophical foundations. The autonomy of the media in relation to the institutional commitment to the state through the war against terrorism can sometimes be as hastily analyzed as a hit if it ignores the difficulties journalists to build autonomous discursive frames. The temptation to put them at the service of "public order" state, or a state of emergency involving a duty of discretion is great for the political authorities.

\section{Three types of recommendations can be drawn from these observations}

First-all reporters, it is important to focus on military issues because of their specificities and not cyclical manner. Because war is an exceptional circumstance but not promised a voluntary disappearance, she brings out of the ordinary circumstances of scheduling armies that involve regular attendance. We must know the rules that are expressed in ordinary grammar institutions but also the circumstances that may shake up, such as wars. Experts strategies that now occupy segments of media consultancy providing substantial insights to the belligerence of situations can be very useful if journalists know ask them the most relevant issues of war commitments. Because of years the market for conventional war, the armies are facing a dual problem. Internally, firstly, the problem is posed by the organizational structures often inadequate because of 
compartmentalization of skills and communication strategies that incorporate too slowly globalization. On the other hand the external level, the management of issues related to this new form of "guerrilla" that is broadcast live and all-round information and the multiple interactions of the players, in turn transmitters, receivers and relay still little control. In military/reporter pairs, replaces a configuration where the communication agency, the "spin doctor" the witness with a digital camera, the alternative media, the internet, blogger, etc., also play their part; to armies that are generously open to the requirements of modern communicative generalizing communication among their ranks and appointing operational specialists, it is important not to consider communication as an exclusively designed to seduce the media operation and whose journalists would only be subordinate and submissive relay. First, because the cognitive confrontation, without death or destruction and spectacular which the blurring of images of dead media echoes, is the logical consequence of the rejection by the people of the world of military warfare. Indeed, the preservation of living standards and material comfort an argument at least as strong as the claim of the democratic ideal to explain the transformation of social representations of war. In France for example, the activities undertaken within the School of economic warfare (EGE) led to pass the Study of War through information to the concept of cognitive war. This is an invitation to formulate a body of doctrines and operational variations. if the United States is observed that it committed a tactical error by focusing their military campaign in Iraq about WMD, they may be gaining a strategic battle in the field of cognitive war. Their control of information vectors does not prejudge their absolute mastery of content they carry. Moreover asymmetric warfare whose generalization is a powerful experience of contemporary society by the rise of non-state actors and terrorists, a problem of a different order in that they have acquired the know-how to give to any attack by an exceptional impact interposed digital. So, their control of information vectors does not prejudge their absolute mastery of content they carry. Moreover asymmetric warfare whose generalization is a powerful experience of contemporary society by the rise of non-state actors and terrorists, a problem of a different order in that they have acquired the know-how to give to any attack by an exceptional impact interposed digital. So, a problem of a different order in that they have acquired the know-how to give to any attack by an exceptional impact interposed digital. So, a problem of a different order in that they have acquired the know-how to give to any attack by an exceptional impact interposed digital. So, "We discover notes Huyghes, the existence of a surprising "market" jihadist image with its subgenres (wills, videos, cassettes on training fighters, collaborators or executions of hostages). «The against-strategies to force these images not only involve saturating that market Converses or contrary images. The derision is this perspective a credible alternative or at least possible. Further professionalization of the War of communication here involves structuring services and institutionalization that requires skill in designing messages and organizational strategies, and technical and financial resources.

\section{Conclusion}

Finally, media education and strategic communication at the main actors of the war (public, journalists, military, and universities) is essential to cognitive institutionalization including the formulation of problems, construction of objects and the constitution of the corpus theoretical and methodological. It would help more public place remote war events as reported by the media and communication from a deep knowledge of their specific operating modes.

\section{Acknowledgments}

None.

\section{Conflicts of interest}

The author declares that there are no conflicts of interest.

\section{References}

1. Huyges François Bernard. Display/enemy: terrorism and wars of Information. "Strategy". Paris: Daech, the weapon of revealed communication, VA Press; 2017. 511 p.

2. Karpik Lucien. An Essay on the Growing Contribution of Economic Markets to the Proliferation of the Social. Gallimard: Library of Humanities press; 2007. 258 p.

3. Servier Jean. Terrorism. Paris: Presses Universitaires de France, Coll; "What do I know?" 1979. $260 \mathrm{p}$ 